\title{
Neonatal resuscitation: advances in training and practice
}

This article was published in the following Dove Press journal:

Advances in Medical Education and Practice

23 December 2016

Number of times this article has been viewed

\section{Taylor Sawyer \\ Rachel A Umoren \\ Megan M Gray}

Department of Pediatrics, Division of Neonatology, Neonatal Education and Simulation-based Training (NEST) Program, University of Washington School of Medicine, Seattle, WA, USA
Correspondence: Taylor Sawyer Department of Pediatrics, Division of Neonatology, Neonatal Education and Simulation-based Training (NEST) Program, University of Washington School of Medicine, 1959 NE Pacific Street, RR45I HSB, Box 356320, Seattle, WA 98195-6320, USA

Tel +l 2065433200

Fax +l 2065438926

Email tlsawyer@uw.edu
Abstract: Each year in the US, some four hundred thousand newborns need help breathing when they are born. Due to the frequent need for resuscitation at birth, it is vital to have evidence-based care guidelines and to provide effective neonatal resuscitation training. Every five years, the International Liaison Committee on Resuscitation (ILCOR) reviews the science of neonatal resuscitation. In the US, the American Heart Association (AHA) develops treatment guidelines based on the ILCOR science review, and the Neonatal Resuscitation Program (NRP) translates the AHA guidelines into an educational curriculum. In this report, we review recent advances in neonatal resuscitation training and practice. We begin with a review of the new 7 th edition NRP training curriculum. Then, we examine key changes to the 2015 AHA neonatal resuscitation guidelines. The four components of the NRP curriculum reviewed here include $\mathrm{eSim}^{\circledR}$, Performance Skills Stations, Integrated Skills Station, and Simulation and Debriefing. The key changes to the AHA neonatal resuscitation guidelines reviewed include initial steps of newborn care, positive-pressure ventilation, endotracheal intubation and use of laryngeal mask, chest compressions, medications, resuscitation of preterm newborns, and ethics and end-of-life care. We hope this report provides a succinct review of recent advances in neonatal resuscitation. Keywords: neonatal resuscitation, Neonatal Resuscitation Program, NRP, simulation, deliberate practice, debriefing, eSIM

\section{Introduction}

Approximately 4,000,000 babies will be born in US this year. ${ }^{1}$ Around 400,000 of these babies will need help breathing and/or positive-pressure ventilation to successfully transition to life outside the womb, and as many as 12,000 will need resuscitation with chest compressions and cardiac medications to survive., ${ }^{2,3}$ Due to the frequent need for resuscitation at birth, it is vital to have birth attendants who are trained to provide neonatal resuscitation to babies in need. In the US, the Neonatal Resuscitation Program (NRP) is the primary educational mechanism used to teach health care providers to perform neonatal resuscitation. The goal of the NRP curriculum is to help neonatal care providers acquire the cognitive, technical, and behavioral skills needed to successfully and efficiently resuscitate babies at the time of birth. ${ }^{4}$

The NRP educational curriculum is reviewed and revised in five years cycles in coordination with the International Liaison Committee on Resuscitation (ILCOR) review of resuscitation science. ${ }^{5}$ Based on the ILCOR science review, the American Heart Association (AHA) developed neonatal resuscitation guidelines and treatment recommendations. ${ }^{6}$ The NRP program then translates the AHA guidelines into an educational curriculum and develops a NRP flow diagram, which is published in the 
Textbook of Neonatal Resuscitation. ${ }^{7}$ This year marks the 7 th edition of the NRP educational curriculum.

In this report, we review recent advances in neonatal resuscitation training and practice. We begin by examining the new 7th edition NRP educational curriculum. Then, we examine key changes to the 2015 AHA neonatal resuscitation guidelines that affect the practice of neonatal resuscitation. We hope this report provides a succinct review of recent advances in neonatal resuscitation.

\section{Advances in training}

The following are six educational components of the NRP 7th edition educational curriculum: 1) self-study of the Textbook of Neonatal Resuscitation, 2) assessment of knowledge via online examination, 3) computer-based practice via NRP $\operatorname{eSim}^{\circledR}$ (Laerdal Medical, Wappingers Falls, NY, USA), 4) Performance Skills Stations, 5) Integrated Skills Station, and 6) Simulation and Debriefing. Advances in the NRP educational curriculum from the sixth to the 7 th edition are summarized in Table 1.

The 7th edition NRP educational curriculum follows an evidence-based framework known as the "Learn-See-Practice-

Table I Advances in the Neonatal Resuscitation Program (NRP) educational curriculum from the 6 th to the 7 th edition

\begin{tabular}{lll}
\hline & Sixth edition NRP & Seventh edition NRP \\
\hline Pre-course & $\begin{array}{l}\text { Self-study of the Textbook } \\
\text { of Neonatal Resuscitation } \\
\text { Online examination }\end{array}$ & $\begin{array}{l}\text { Self-study of the Textbook of } \\
\text { Neonatal Resuscitation } \\
\text { Online examination } \\
\text { NRP eSim }{ }^{\circledR}\end{array}$ \\
$\begin{array}{ll}\text { During the } \\
\text { course }\end{array}$ & Performance Skills Stations Performance Skills Stations \\
& $\begin{array}{l}\text { Integrated Skills Station } \\
\text { Simulation and Debriefing }\end{array}$ & $\begin{array}{l}\text { Integrated Skills Station } \\
\text { Simulation and Debriefing }\end{array}$ \\
\hline
\end{tabular}

Prove-Do-Maintain" (LSPPDM) pedagogy. ${ }^{8}$ The LSPPDM pedagogy is a six-phase framework for teaching procedural skills, assessing competency, and maintaining competency once acquired. When applied to the NRP curriculum, the LSPPDM pedagogy is used as follows. The first phase, "Learn", is facilitated by self-study of the Textbook of Neonatal Resuscitation, passing the online examination, and doing the online eSim $^{\circledR}$ module. During the NRP course, students "See" the techniques of neonatal resuscitation demonstrated by the instructor, and "Practice" the skills using simulation during the Performance Skills Stations, and Simulation and Debriefing. During the Integrated Skills Station, the students "Prove" their proficiency in neonatal resuscitation. After course completion, students go on to "Do" neonatal resuscitation as part of clinical care. Students "Maintain” neonatal resuscitation skill through clinical practice, supplemented by simulation-based training as needed and participation in an NRP course every two years. Figure 1 provides an overview of the LSPPDM pedagogy applied to the NRP curriculum. The following are the four components of the NRP curriculum reviewed: $\mathrm{eSim}^{\circledR}$, Performance Skills Stations, Integrated Skills Station, and Simulation and Debriefing.

\section{NRP eSim ${ }^{\circledR}$}

Before attending the 7th edition NRP course, students are required to complete at least two simulated resuscitation scenarios through the online eSim ${ }^{\circledR}$ platform. The NRP eSim ${ }^{\circledR}$ is a screen-based simulator designed by Laerdal Medical in collaboration with the American Academy of Pediatrics. NRP $\mathrm{eSim}^{\circledR}$ allows a single user to resuscitate a virtual newborn in order to learn the steps of neonatal resuscitation (Figure 2). The simulated resuscitation can be performed by the student from

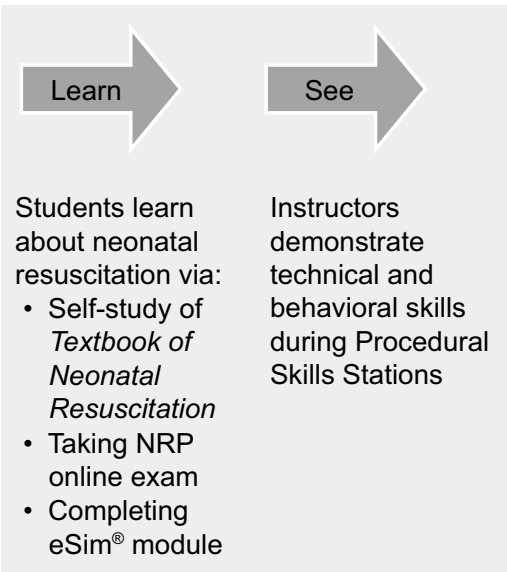

Cognitive phase

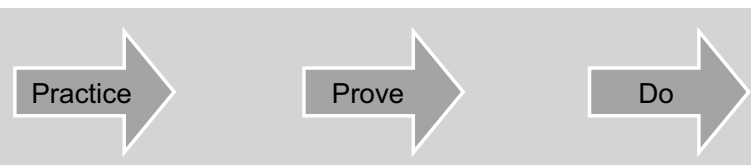

Students practice technical and behavioral skills during Procedural Skills Stations and Simulation and Debriefing
Summative assessment is done during the Integrated Skills Station - this is where students pass or fail the NRP course
After the NRP course, students perform neonatal resuscitation during clinical care

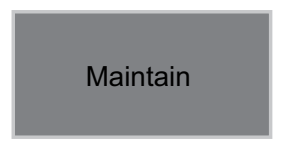

Students maintain skill through clinical practice supplemented by simulation as needed and attendance of a NRP course every two years

Psychomotor phase

Figure I LSPPDM pedagogy applied to the Neonatal Resuscitation Program (NRP) curriculum.

Note: Sawyer T, White M, Zaveri P, et al. Learn, see, practice, prove, do, maintain: an evidence-based pedagogical framework for procedural skill training in medicine. Acad Med. 2015;90(8):1025-1033. http://journals.Iww.com/academicmedicine/Fulltext/2015/08000/Learn,_See,_Practice,_Prove,_Do,_Maintain__An.13.aspx. Abbreviation: LSPPDM, Learn-See-Practice-Prove-Do-Maintain. 


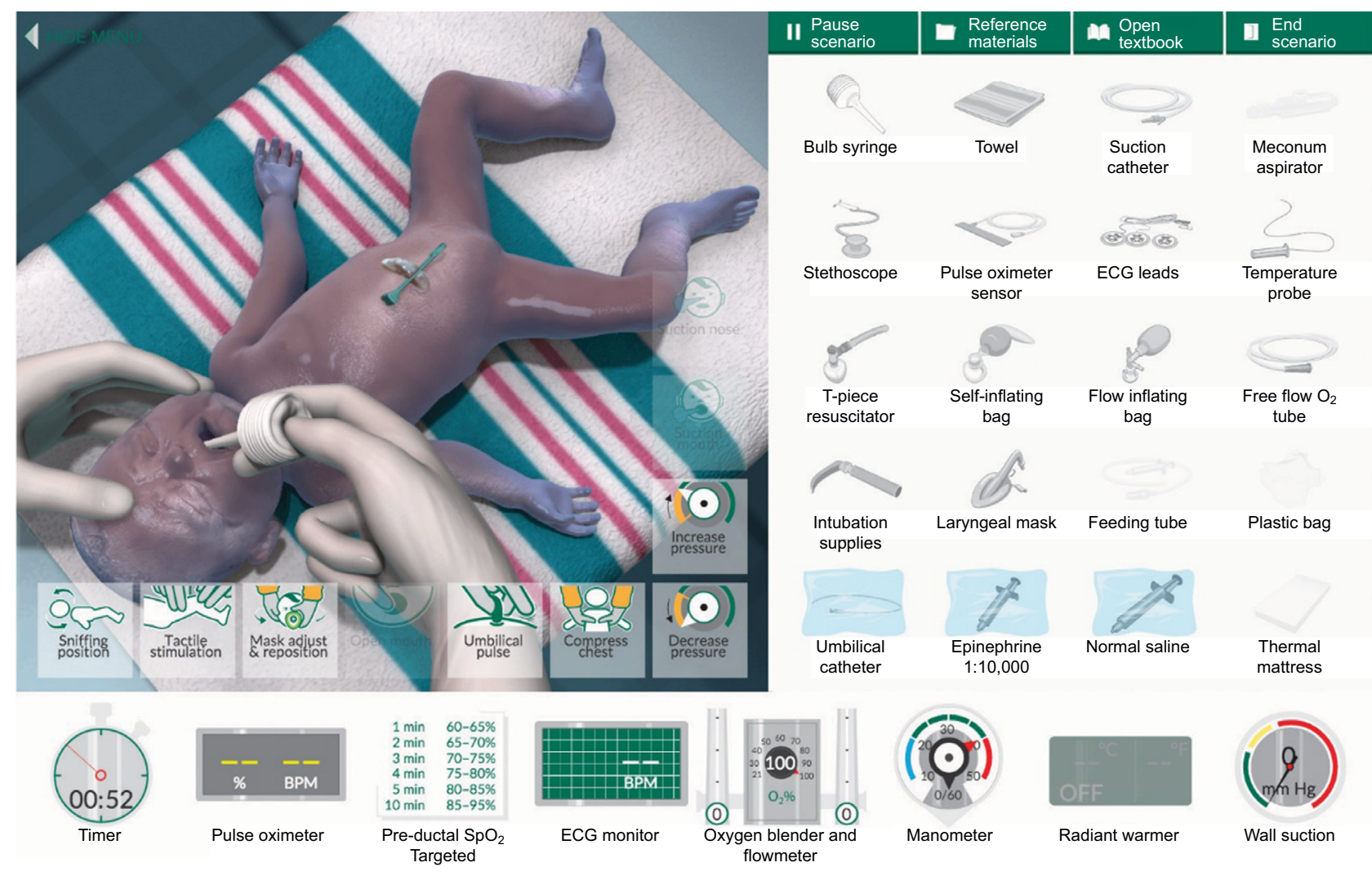

Figure 2 Screenshot of the Neonatal Resuscitation Program (NRP) eSim ${ }^{\circledR}$ module.

Note: From Weiner GM, editor. Textbook of Neonatal Resuscitation (NRP). 7th ed. Elk Grove Village, IL: American Academy of Pediatrics; 20I6: I0. Copyright (C 20I6 American Academy of Pediatrics. Reproduced with permission.

Abbreviation: ECG, electrocardiography.

any computer at a time in a convenient location. Each eSim ${ }^{\circledR}$ scenario starts with a brief case overview that provides pertinent prenatal history. After the case introduction, students start the scenario with an equipment check that includes adjustment of the fraction of inspired oxygen, positive-pressure ventilation setting, and suction pressure. Once the equipment is prepared, students begin the simulation scenario. To simulate the steps of resuscitation on the screen-based simulator, students "drag and drop" equipment such as a towel, stethoscope, and T-piece resuscitator over the infant. The infant responds to the student's actions based on a physiologic model. Each scenario requires different resuscitation measures for effective resuscitation. Upon completion of the scenario, students receive automated feedback for self-reflection. There is no "pass" or "fail" in the $\mathrm{eSim}^{\circledR}$ module. Students can repeat any of the four $\mathrm{eSim}^{\circledR}$ scenarios as many times as they want. Figure 2 displays a screenshot from the NRP eSim ${ }^{\circledR}$ module, showing the virtual neonate and the actions and equipment available to the student.

\section{Performance Skills Stations}

The NRP course begins with Performance Skills Stations. At these stations, instructors demonstrate the correct performance of the skills required during neonatal resuscitation, including positive-pressure ventilation, laryngeal mask placement, tracheal intubation, chest compressions, placement of an emergency umbilical catheter, and administration of medications. They also demonstrate behavioral and teamwork skills. After demonstration, the students deliberately practice with expert coaching by the instructor. Deliberate practice continues until the students can perform the skills with minimal coaching. Each skill builds on the next, and can be integrated into brief training scenarios. By the end of the Performance Skills Stations, the students have repeatedly practiced all the steps of the NRP flow diagram. This instructional methodology aligns well with Ericsson's deliberate practice paradigm that advocates for repeated practice combined with focused feedback. ${ }^{9}$ Advanced students are allowed to skip the Performance Skills Stations and start the NRP course with the Integrated Skills Station, with the assumption that they have already mastered the skills of neonatal resuscitation and are well-versed in the NRP flow diagram.

\section{Integrated Skills Station}

Students are required to prove their proficiency in neonatal resuscitation during the Integrated Skills Station. The Integrated Skills Station consolidates learning by integrating the 
individual technical and behavioral skills of students for neonatal resuscitation into mini-simulation scenarios. The student being evaluated leads the resuscitation team during the scenario, receiving minimal help or guidance from his/her team. During these scenarios, the student demonstrates that he/she can follow the NRP flow diagram in proper sequence. At this point, the NRP instructor determines if the student passes the NRP course. It is important to note that completion of the NRP course does not imply that a student is competent to perform neonatal resuscitation. Each hospital and care organization is required to determine the competency of its providers. ${ }^{7}$

\section{Simulation and Debriefing}

After practicing the technical and behavioral skills in the Performance Skills Stations, and proving their proficiency in the Integrated Skills Station, students participate in teambased neonatal resuscitation Simulation and Debriefing. The Simulation and Debriefing part of the course continues to reinforce cognitive and technical skills, but mainly focuses on the 10 NRP key behavioral skills. ${ }^{7}$ The simulation scenarios mimic clinical cases that resuscitation team members are expected to manage and challenge the students to work together as a team to follow the NRP flow diagram.

Debriefing is the most important part of the Simulation and Debriefing process of the NRP course. ${ }^{10}$ Debriefing provides a method of reflection on action and is a form of what Schön calls "reflective practice". ${ }^{11}$ Kolb experiential learning theory, which describes how experience results in learning and personal development, relies on reflection on action as a core principle. ${ }^{12}$ The central theme of both reflective practice and experiential learning is that experience alone does not lead to learning, but rather a deliberate reflection on the experience leads to learning.

There are many methods for conducting simulation and debriefing. ${ }^{13}$ Debriefing in the NRP course uses a method known as facilitator-guided post-event debriefing. Using this method the debriefing conversation occurs after completion of the simulation scenario, and is guided by the instructor who acts as the debriefing facilitator. A suggested structure for the debriefing conversations is the "Gather, Analyze, and Summarize" (GAS) format developed by Phrampus et al. ${ }^{14}$ Using the GAS format, the debriefing process starts with a quick review of resuscitation events to gather data and establish a shared mental model among the team members. Next, the events of the resuscitation are analyzed using a "plus-delta" method in which students first review what went well (plus), and then what could be improved (delta). Debriefing concludes with students summarizing the important learning points and a discussion of how they will change their performance in subsequent resuscitation scenarios. A suggested conversational structure for debriefing in the NRP course is available. ${ }^{10}$

According to the NRP flow diagram, post-event debriefing should occur after every neonatal resuscitation. These post-event clinical debriefings can follow the same GAS format and plus/delta method used in the NRP course. ${ }^{15}$ Using the same debriefing method during the NRP course and during clinical care allows neonatal care providers to gain familiarity and proficiency with post-event debriefing, allowing debriefing to become a standard practice.

\section{Advances in practice}

As mentioned earlier, the science that supports neonatal resuscitation practice is reviewed every five years by the ILCOR. The data are summarized in the International Consensus on Cardiopulmonary Resuscitation and Emergency Cardiovascular Care Science with treatment recommendations and translated into AHA neonatal resuscitation guidelines in the US. ${ }^{5,6}$ A summary of the advances in neonatal resuscitation practice with the 2015 guidelines is provided below and summarized in Table 2 . These changes become the standard of care in the US from January 2017.

\section{Initial steps of newborn care}

Every neonatal resuscitation should begin with a team briefing and equipment check. ${ }^{7}$ During the briefing, the reason for delivery attendance is reviewed, team members introduce themselves and are assigned roles by the team leader. All the pieces of equipment are then checked to ensure they work, and settings for positive-pressure ventilation, fraction of inspired oxygen and suction are confirmed.

Delaying umbilical cord clamping for 30-60 seconds is recommended in all vigorous term and preterm newborns. ${ }^{5,6}$ In cases where placental circulation is not intact, delayed cord clamping is not recommended. Such cases include cord avulsion, placental abruption, and bleeding placenta previa or vasa previa. If the infant is not vigorous and requires resuscitation at birth, it is unclear whether or not clamping of the cord should be delayed. In these cases, the decision to delay cord clamping, or clamp immediately and start resuscitation, is left to the neonatal care providers and to hospital authorities.

Intubation and suction of the airway with an endotracheal tube are no longer recommended for non-vigorous infants born through meconium-stained amniotic fluid. ${ }^{6}$ After a review of resuscitation science, ILCOR determined there is insufficient evidence to continue this practice. ${ }^{5}$ Gentle 
Table 2 Advances in neonatal resuscitation practice with the 2015 guidelines

\begin{tabular}{|c|c|}
\hline Initial steps of newborn care & $\begin{array}{l}\text { - Begin every resuscitation with a team briefing and equipment check } \\
\text { - Delay umbilical cord clamping for } 30-60 \text { seconds in vigorous term and preterm newborns } \\
\text { - Do not intubate and suction the airway in non-vigorous infants born through meconium-stained fluids } \\
\text { - Assess heart rate via auscultation with a stethoscope }\end{array}$ \\
\hline Positive-pressure ventilation (PPV) & $\begin{array}{l}\text { - Ensure PPV results in visible "chest movement" } \\
\text { - Use a rising heart rate as the physiologic indicator of effective PPV }\end{array}$ \\
\hline $\begin{array}{l}\text { Endotracheal intubation and laryngeal } \\
\text { mask }\end{array}$ & $\begin{array}{l}\text { - Perform endotracheal intubation prior to starting chest compressions } \\
\text { - Use "Initial Endotracheal Tube Insertion Depth" table or the newborn's nasal-tragus length (NTL) }+1 \mathrm{~cm} \\
\text { to determine proper endotracheal tube depth } \\
\text { - Use a laryngeal mask if tracheal intubation is not successful or not feasible due to lack of trained personnel }\end{array}$ \\
\hline Chest compressions & $\begin{array}{l}\text { - Use electrocardiography (ECG) to accurately assess heart rate } \\
\text { - Continue chest compressions for } 60 \text { seconds before stopping to check the heart rate }\end{array}$ \\
\hline Medications & $\begin{array}{l}\text { - Do not use Lactated Ringers or sodium bicarbonate } \\
\text { - Give epinephrine if the heart rate remains less than } 60 \mathrm{bpm} \text { despite } 30 \text { seconds of effective PPV that } \\
\text { moves the chest, and another } 60 \text { seconds of coordinated chest compression and ventilations using } \\
100 \% \text { oxygen } \\
\text { - If an endotracheal dose of epinephrine is used, give a repeat intravenous dose as soon as vascular access is } \\
\text { obtained; do not wait } 3-5 \text { minutes after the endotracheal dose }\end{array}$ \\
\hline Resuscitation of preterm newborns & $\begin{array}{l}\text { - Delivery room temperature should be set at } \sim 23^{\circ} \mathrm{C}-25^{\circ} \mathrm{C}\left(74^{\circ} \mathrm{F}-77^{\circ} \mathrm{F}\right) \\
\text { - A thermal mattress, plastic wrap or bag, and a hat should be used for premature newborns less than } \\
32 \text { weeks' gestation } \\
\text { - CPAP can be used immediately after birth in premature newborns with respiratory distress syndrome as } \\
\text { an alternative to routine intubation and prophylactic surfactant administration }\end{array}$ \\
\hline Ethics and end-of-life care & $\begin{array}{l}\text { - In cases of birth at less than } 22 \text { weeks' gestation, and some chromosomal anomalies and congenital } \\
\text { malformations where there is no chance for survival, neonatal resuscitation is not ethical and should not } \\
\text { be offered } \\
\text { - In cases where survival is uncertain and there is a high risk of morbidity, such as birth between } 22 \text { and } 24 \\
\text { weeks' gestation and some chromosomal anomalies and congenital malformations, the parents should be } \\
\text { included in decisions regarding resuscitation plans }\end{array}$ \\
\hline
\end{tabular}

Abbreviations: CPAP, continuous positive airway pressure; bpm, beats per minute.

suctioning of the mouth and nose with a bulb syringe can be done for infants born through meconium. ${ }^{7}$

Assessment of the heart rate in a newborn is most accurately done via auscultation with a stethoscope. ${ }^{5}$ Palpation of the umbilical cord is less accurate and may lead to an underestimation of the actual heart rate. If the heart rate cannot be determined by auscultation, then a pulse oximeter or electrocardiography (ECG) should be used. ${ }^{5}$

\section{Positive-pressure ventilation}

The most critical action in neonatal resuscitation is ventilation of the baby's lungs. ${ }^{5-7}$ Positive-pressure ventilation is indicated in apneic and gasping newborns, and those with a heart rate less than 100 beats per minute (bpm). An initial peak inspiratory pressure (PIP) of $20-25 \mathrm{~cm} \mathrm{H}_{2} \mathrm{O}$ and a peak end-expiratory pressure of $5 \mathrm{~cm} \mathrm{H}_{2} \mathrm{O}$ are recommended when administering positive-pressure ventilation. ${ }^{7}$ Movement of the chest is the preferred method to confirm ventilation of the lungs. ${ }^{6} \mathrm{~A}$ rising heart rate is the best physiologic indicator of effective positive-pressure ventilation. ${ }^{6}$ The heart rate should be followed closely during positive-pressure ventilation to ensure that it is being given effectively. Providers should consider using ECG when positive-pressure ventilation begins in order to accurately follow the heart rate.

To determine whether or not positive-pressure ventilation is effective, one team member should auscultate the heart rate during the first 15 seconds of positive-pressure ventilation. If the chest is moving and the heart rate is increasing or stable, then positive-pressure ventilation will continue for another 15 seconds, after which the heart rate is reassessed. If the chest is not moving and the heart rate is not increasing, ventilation corrective steps should be followed until the chest moves with ventilation. The order of ventilation corrective steps is as follows: 1) reapplication of the mask, 2) repositioning of the head, 3) suctioning of the airway with a bulb syringe, 4) opening of the mouth, 5) increase in PIP, and 6) placement of an alternative airway. The pneumonic "MR. SOPA" is used to remember these six steps. ${ }^{7}$ These maneuvers should be performed in a stepwise manner with reapplication of the mask and repositioning of the head first, followed by several breaths and auscultation of the heart rate. If the chest is not moving, then suctioning and opening of the 
mouth should be performed, and PIP should be titrated up to a maximum of $40 \mathrm{~cm} \mathrm{H}_{2} \mathrm{O}$ as needed in order to achieve chest rise.

After completion of any needed ventilation corrective steps, 30 seconds of positive-pressure ventilation that moves the chest should be given and the heart rate should be reassessed. If the heart rate is at least $100 \mathrm{bpm}$, then positivepressure ventilation could be continued at 40-60 breaths/ minute until spontaneous breathing starts. If the heart rate is less than $60 \mathrm{bpm}$ or between 60 and $99 \mathrm{bpm}$, then the effectiveness of ventilation is reassessed, including repeating ventilation corrective steps if necessary. If the heart rate remains less than $60 \mathrm{bpm}$ with positive-pressure ventilation that moves the chest, then an alternative airway (endotracheal tube or laryngeal mask) should be inserted. If the heart rate does not increase with an advanced airway in place, then chest compressions should be started.

Positive-pressure ventilation in newborns at 35 weeks' gestation or greater should begin with $21 \%$ oxygen. ${ }^{5,6}$ Positive-pressure ventilation in newborns born earlier than 35 weeks' gestation should begin with oxygen levels between $21 \%$ and $30 \%$, depending on local practice. Supplemental oxygen can be started at $30 \%$, and titrated as needed, in newborns who are breathing but not maintaining oxygen saturation levels within the target range. Supplemental oxygen concentration should be titrated to keep oxygen saturation in the target range found in the NRP flow diagram. ${ }^{7} \mathrm{~A}$ trial of continuous positive airway pressure (CPAP) can be considered in newborns with labored breathing and those not maintaining oxygen saturation within the target range with $100 \%$ supplemental oxygen.

\section{Endotracheal intubation and laryngeal mask}

Placement of an endotracheal tube into the trachea is the definitive method to secure the airway in a newborn who is persistently apneic, has significant respiratory distress, or remains bradycardic with a heart rate less than $60 \mathrm{bpm}$ despite providing positive-pressure ventilation via face mask that moves the chest. Intubation is recommended before beginning chest compressions in order to ensure that effective ventilation is being provided. ${ }^{6}$ The steps of performing neonatal intubation are outlined in the Textbook of Neonatal Resuscitation. ${ }^{7}$ Recommended sizes of endotracheal tubes and laryngeal masks for newborns are provided in Table 3.

In the past, correct endotracheal tube depth was estimated using the vocal cord guide on the endotracheal tube, or the formula " $6+$ the weight in kilograms" (e.g. for a $3 \mathrm{~kg}$ baby the estimated correct depth was $9 \mathrm{~cm}$ at the lip $[6+3=9]$ ).
Table 3 Endotracheal tube and laryngeal mask sizes for newborns

\begin{tabular}{llll}
\hline $\begin{array}{l}\text { Gestational age } \\
\text { (weeks) }\end{array}$ & Weight $(\mathbf{g})$ & $\begin{array}{l}\text { Endotracheal } \\
\text { tube size }(\mathbf{m m})\end{array}$ & $\begin{array}{l}\text { Laryngeal } \\
\text { mask size }\end{array}$ \\
\hline$<28$ & $<1,000$ & 2.5 & $\mathrm{~N} / \mathrm{A}$ \\
$28-34$ & $\mathrm{I}, 000-2,000$ & 3.0 & $\mathrm{I}$ \\
$>34$ & $>2,000$ & 3.5 & $\mathrm{I}$ \\
\hline
\end{tabular}

Note: Data from Weiner et al. ${ }^{7}$

Abbreviation: N/A, not applicable.

With the new guidelines, correct endotracheal tube depth is determined using the "Initial Endotracheal Tube Insertion Depth" table or by measuring the newborn's nasal-tragus length (NTL) and adding $1 \mathrm{~cm}^{7}$ The NTL is the distance from the base of the nasal septum to the tip of the tragus of the ear. These two methods are considered more accurate than previous methods. However, they are still only estimates of correct insertion depth. After the endotracheal tube is placed, auscultation of breath sounds and use of a $\mathrm{CO}_{2}$ detector are recommended to confirm correct endotracheal tube placement.

If tracheal intubation is not successful after several attempts or not feasible due to lack of trained personnel, then a laryngeal mask should be used. A laryngeal mask is recommended during resuscitation of newborns at 34 weeks' gestation or greater and weighing 2,000 g or more. ${ }^{7}$ Data on laryngeal mask use in preterm infants less than 34 weeks' gestation are limited; however, several reports describe their successful use in infants weighing less than $1,500 \mathrm{~g} .{ }^{16,17} \mathrm{~A}$ recent study of the effectiveness of laryngeal mask by Trevisanuto et al found that in newborns with a gestational age of 34 weeks and/or expected birth weight of 1,500 g needing positive-pressure ventilation at birth, the laryngeal mask was more effective than the face mask to prevent endotracheal intubation. ${ }^{18}$ Additionally, the laryngeal mask was effectively implemented in clinical practice after only a short educational intervention. ${ }^{18}$ Laryngeal mask use has not been evaluated during chest compressions. However, if it is not feasible to intubate or intubation is unsuccessful after several attempts, it is reasonable to start compressions with the laryngeal mask in place. ${ }^{7}$

\section{Chest compressions}

The preferred method to administer chest compressions in a newborn is the two-thumb technique, where the person performing compressions wraps his/her hands around the newborn's chest and compresses the sternum with both thumbs. Once started, chest compressions should continue for 60 seconds before the team pauses compressions and checks the heart rate again. This limits interruptions in compressions and may improve coronary artery perfusion. ${ }^{19}$ Once an 
endotracheal tube or laryngeal mask is inserted and secured, the person performing compressions should administer chest compressions from the head of the newborn to free up space over the newborn's abdomen for another provider to place an emergency umbilical catheter (Figure 3). During neonatal resuscitation, chest compression should always be synchronized with ventilation in a 3:1 ratio, regardless of the presence of an advanced airway. The goal chest compression rate is 90 compressions per minute synchronized with $30 \mathrm{bpm}$ and given with a cadence of "one-and-two-and-three-andbreath". With the start of chest compressions, supplemental oxygen should be increased to $100 \%$ in order to maximize systemic oxygen delivery. ${ }^{5}$ An ECG is the preferred method for assessing the heart rate during chest compressions, and ECG leads should be placed on the newborn's chest when compressions begin.

\section{Medications}

The only two medications included in the neonatal resuscitation guidelines are epinephrine and normal saline $(0.9 \%$ $\mathrm{NaCl}) .{ }^{6}$ Neither sodium bicarbonate nor Ringer's Lactate is recommended during neonatal resuscitation. Epinephrine should be given if the heart rate stays less than $60 \mathrm{bpm}$ despite providing 30 seconds of effective positive-pressure ventilation that moves the chest, and another 60 seconds of coordinated chest compressions and ventilations using $100 \%$ oxygen. Epinephrine should not be given before effective ventilation that moves the chest has been established. Once given, epinephrine can be administered every 3-5 minutes if the heart rate remains less than $60 \mathrm{bpm}$. The recommended intravenous dose of epinephrine is $0.01-0.03$ $\mathrm{mg} / \mathrm{kg}$, or $0.1-0.3 \mathrm{ml} / \mathrm{kg}$, of a $1: 10,000$ concentration. ${ }^{6}$ The recommended endotracheal dose is $0.05-0.1 \mathrm{mg} / \mathrm{kg}$, or $0.5-1 \mathrm{ml} / \mathrm{kg}$, of a $1: 10,000$ concentration. ${ }^{6}$ The preferred route for epinephrine is intravenous due to the concerns regarding absorption from the lungs after administration of endotracheal tube..$^{5}$ However, one dose of endotracheal epinephrine may be considered while intravenous access is being obtained. If an endotracheal dose of epinephrine is given, a repeat intravenous dose should be given as soon as vascular access is obtained. ${ }^{6}$ In such a case, there is no need to wait 3-5 minutes after the endotracheal dose. The preferred method to establish vascular access during neonatal resuscitation is to place an emergency umbilical catheter, although an intraosseous needle can also be considered. ${ }^{6}$ If there are concerns of acute hypovolemia, a normal saline bolus of $10 \mathrm{ml} / \mathrm{kg}$ can be administered using the emergency umbilical catheter or intraosseous needle. ${ }^{6}$ In cases of significant blood loss, uncrossmatched type-O negative blood can be used to emergently treat acute anemia.

\section{Resuscitation of preterm newborns}

In preparation for resuscitation of a premature newborn, the temperature in the delivery room should be increased to $23^{\circ} \mathrm{C}-25^{\circ} \mathrm{C}\left(74^{\circ} \mathrm{F}-77^{\circ} \mathrm{F}\right) .^{5}$ For premature newborns born before 32 weeks' gestation, the resuscitation team should ensure normothermia by 1) placing a thermal mattress under the newborn, 2) using plastic wrap or a bag to cover the newborn, and 3) placing a hat on the newborn's head immediately after delivery. ${ }^{7}$ The goal axillary temperature in a newborn during resuscitation is between $36.5^{\circ} \mathrm{C}$ and $37.5^{\circ} \mathrm{C} .^{5}$

Many premature newborns have respiratory distress at delivery due to lung immaturity and surfactant deficiency. If positive-pressure ventilation is given during the resuscitation of a preterm newborn, a T-piece device that can deliver CPAP is preferred. Using CPAP keeps the newborn's lungs inflated and helps to establish functional residual capacity. CPAP can be used immediately after birth in premature newborns with respiratory distress syndrome as an alternative to routine intubation and prophylactic surfactant administration. ${ }^{5}$ The use of early CPAP may avoid the need for intubation and mechanical ventilation in many cases. ${ }^{20}$
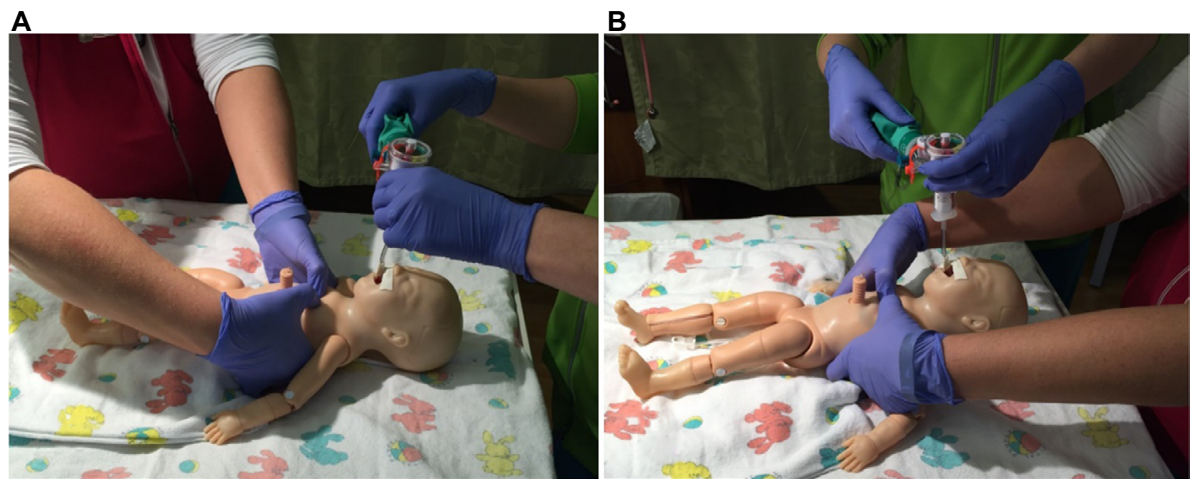

Figure 3 Chest compression administered from the foot of the bed $(\mathbf{A})$ and the head of the bed (B). 


\section{Ethics and end-of-life care}

In rare cases, there is no chance for survival of a newborn after delivery. In such cases, initiation of neonatal resuscitation is not ethical and should not be offered. Examples of such cases include birth at less than 22 weeks' gestation, some chromosomal anomalies, and congenital malformations. ${ }^{7}$ This is a change from earlier guidelines which suggested a lower limit of viability at less than 23 weeks' gestation and a birth weight of less than $400 \mathrm{~g} .{ }^{21}$ In cases where survival is uncertain or there is a high risk of morbidity, the parents should be included in decisions regarding resuscitation plans. ${ }^{7}$ Such cases include birth between 22 and 24 weeks' gestation, some chromosomal anomalies, and congenital malformations. In these cases, after appropriate prenatal counseling, the parent's desires should guide resuscitation efforts.

\section{Conclusion}

In this report, we reviewed recent advances in neonatal resuscitation training and practice including the 7 th edition NRP educational curriculum and the 2015 AHA neonatal resuscitation guidelines. This year marks the 29th anniversary of the NRP. The 7th edition NRP curriculum continues a long tradition of improving the cognitive, technical, and behavioral skills of providers responsible for resuscitating newborns. We hope that these changes in the educational curriculum and the resuscitation guidelines will help to save the lives of many newborns. Continued advances in neonatal resuscitation training and practice will occur over the next five years in anticipation of the 8th edition NRP educational curriculum and 2020 AHA neonatal resuscitation guidelines. As with the release of the 2015 guidelines, release of the 2020 guidelines will mark the continued efforts of the worldwide neonatology community to optimize the practice of neonatal resuscitation.

\section{Acknowledgments}

Dr. Sawyer acknowledges his collaborators in the International Network for Simulation-based Pediatric Innovation, Research, and Education (INSPIRE) for their work in developing the LSPPDM pedagogy, and the help of Dr. Louis Halamek in delineating the post-event debriefing conversational method referenced here.

\section{Disclosure}

The authors report no conflicts of interest in this work.

\section{References}

1. Hamilton BE, Martin JA, Osterman MJ. Births: preliminary data for 2015. Natl Vital Stat Rep. 2016;65(3):1-15.

2. Perlman JM, Risser R. Cardiopulmonary resuscitation in the delivery room: associated clinical events. Arch Pediatr Adolesc Med. 1995;149(1):20-25.

3. Barber CA, Wyckoff MH. Use and efficacy of endotracheal versus intravenous epinephrine during neonatal cardiopulmonary resuscitation in the delivery room. Pediatrics. 2006;118(3):1028-1034.

4. Halamek LP. Educational perspectives: the genesis, adaptation, and evolution of the neonatal resuscitation program. NeoReviews. 2008;9(4):e142-e149.

5. Perlman JM, Wyllie J, Kattwinkel J, et al; Neonatal Resuscitation Chapter Collaborators. Part 7: Neonatal Resuscitation: 2015 International consensus on cardiopulmonary resuscitation and emergency cardiovascular care science with treatment recommendations. Circulation. 2015;132(16 Suppl 1):S204-S241.

6. Wyckoff MH, Aziz K, Escobedo MB, et al. Part 13: Neonatal Resuscitation: 2015 American Heart Association guidelines update for cardiopulmonary resuscitation and emergency cardiovascular care. Circulation. 2015;132:S543-S560

7. Weiner GM, Zaichkin J, Kattwinkel J, editors. Textbook of Neonatal Resuscitation. 7th ed. Elk Grove Village, IL: American Academy of Pediatrics and American Heart Association; 2016.

8. Sawyer T, White M, Zaveri P, et al. Learn, see, practice, prove, do, maintain: an evidence-based pedagogical framework for procedural skill training in medicine. Acad Med. 2015;90(8):1025-1033.

9. Ericsson KA. Deliberate practice and the acquisition and maintenance of expert performance in medicine and related domains. Acad Med. 2004;79(10 Suppl):S70-S81.

10. Sawyer T, Ades A, Ernst K, Colby C. Simulation and the neonatal resuscitation program 7th edition curriculum. NeoReviews. 2016;17(8): e447-e453.

11. Schön DA. The Reflective Practitioner: How Professionals Think In Action. New York: Basic Books; 1983.

12. Kolb DA. Experiential Learning: Experience as The Source Of Learning and Development. Englewood Cliffs, NJ: Prentice Hall; 1984.

13. Sawyer T, Eppich W, Brett-Fleegler M, Grant V, Cheng A. More than one way to debrief: a critical review of healthcare simulation debriefing methods. Simul Healthc. 2016;11(3):209-217.

14. Phrampus P, O'Donnell J. Debriefing using a structured and supported approach. In: Levine A, Demaria S, Schwarz A, editors. The Comprehensive Textbook of Healthcare Simulation. 1st ed. New York, NY: Springer; 2013:73-84.

15. Sawyer T, Loren D, Halamek LP. Post-event debriefings during neonatal care: why are we not doing them, and how can we start? J Perinatol. 2016;36(6):415-419.

16. Brimacombe J, Gandini D. Airway rescue and drug delivery in an $800 \mathrm{~g}$ neonate with the laryngeal mask airway. Paediatr Anaesth. 1999;9(2):178.

17. Velankar P, Joshi M, Sahu P. Use of laryngeal mask airway in premature infant. Indian J Anaesth. 2013;57(6):634-635.

18. Trevisanuto D, Cavallin F, Nguyen LN, et al. Supreme laryngeal mask airway versus face mask during neonatal resuscitation: a randomized controlled trial. J Pediatr. 2015;167(2):286-291.

19. Kapadia V, Wyckoff MH. Chest compressions for bradycardia or asystole in neonates. Clin Perinatol. 2012;39(4):833-842.

20. Papile LA, Polin RA, Carlo WA, et al; Committee on Fetus and Newborn; American Academy of Pediatrics. Respiratory support in preterm infants at birth. Pediatrics. 2014;133(1):171-174.

21. Kattwinkel J, Perlman JM, Aziz K, et al. Part 15: Neonatal resuscitation: 2010 American Heart Association guidelines for cardiopulmonary resuscitation and emergency cardiovascular care. Circulation. 2010;122(18 Suppl 3):S909-S919. 
Advances in Medical Education and Practice

Dovepress

\section{Publish your work in this journal}

Advances in Medical Education and Practice is an international, peerreviewed, open access journal that aims to present and publish research on Medical Education covering medical, dental, nursing and allied health care professional education. The journal covers undergraduate education, postgraduate training and continuing medical education including emerging trends and innovative models linking education, research, and health care services. The manuscript management system is completely online and includes a very quick and fair peer-review system. Visit http://www.dovepress.com/testimonials.php to read real quotes from published authors.

Submit your manuscript here: http://www.dovepress.com/advances-in-medical-education-and-practice-journal 